\title{
Gradient DLC-Based Nanocomposite Coatings as a Solution to Improve Tribological Performance of Aluminum Alloy
}

\author{
Liping Wang • Shanhong Wan $\cdot$ S. C. Wang • \\ R. J. K. Wood • Q. J. Xue
}

Received: 14 November 2009/Accepted: 18 February 2010/Published online: 4 March 2010

(C) Springer Science+Business Media, LLC 2010

\begin{abstract}
The low hardness and poor tribological performance of aluminum alloy as moving component greatly restricts their wide applications in automotive fields. In this letter, an attempt to deposit gradient Ti/TiN/Si/(TiC/a-C:H) multi-layer on aluminum alloy is thus effectively performed by a combined arc ion plating and magnetron sputtering process based on the concept of involving coatings with a functionally graded interface. Multi-layered structure within DLC-based coatings has shown to significantly improve the load-bearing capacity, anti-wear and self-lubricating ability of $\mathrm{Al}$ alloys. The friction coefficient of gradient DLC-based coatings decreased to 0.18 under dry sliding condition while kept at 0.05 under the oillubricated conditions. The wear rate of gradient DLC multilayers was lower by two and even three orders of magnitude when compared with $\mathrm{Al}$ alloys both under dry wear and oil-lubricated conditions. Such gradient DLCbased coatings with good adhesion strength, high hardness, and excellent tribological performance are considered as potential protective surfaces of $\mathrm{Al}$ alloys for engine parts.
\end{abstract}

Keywords Aluminum alloy · Diamond-like carbon coatings · Graded and multilayer · Friction · Adhesion wear

L. Wang $(\bowtie) \cdot$ S. Wan · Q. J. Xue

State Key Laboratory of Solid Lubrication, Lanzhou Institute of Chemical Physics, Chinese Academy of Sciences, Lanzhou 730000, People's Republic of China

e-mail: lpwang@1zb.ac.cn

S. C. Wang · R. J. K. Wood

national Centre for Advanced Tribology at Southampton (nCATS), School of Engineering Sciences, University

of Southampton, SO17 1BJ Southampton, UK

\section{Introduction}

The growing demand for more fuel-efficient vehicles to reduce oil consumption and $\mathrm{CO}_{2}$ emission is a challenge for the automotive industry. The characteristic properties of aluminum alloys including high strength stiffness/weight ratio, good machinability, high corrosion resistance, and recycle ability make it the ideal candidate to replace steel for weight reduction demand in automotive industry [1]. However, its low hardness, low seizure load, and poor tribological performance have prevented their direct usage in moving parts like cylinder bores, pistons, tappets, and bearings $[1,2]$.

The possible approach to respond to these environmental and tribological requirements is the potential use of high-hardness, self-lubricating, and wear resistant coatings on aluminum alloys which usually experiences variable serving circumstances such as near-dry and dry friction, oil-lubricated, oil-lack, and boundary lubrication conditions. The high hardness, low friction nature, excellent wear and corrosion resistance, and high chemical stability of diamond-like carbon (DLC) coatings make them good candidates as protective layers for aluminum alloys in engine applications [3]. Among DLC coatings, nanocomposite coatings consisting of nanocrystalline ceramic particles embedded in an amorphous hydrocarbon $(\mathrm{a}-\mathrm{C}: \mathrm{H})$ matrix are able to combine high fracture toughness and wear resistance with a low friction coefficient. An example of these a-C(:H) based nanocomposite coatings is the $\mathrm{TiC} /$ $\mathrm{a}-\mathrm{C}: \mathrm{H}$ system [4]. Unfortunately, the abrupt changes in hardness and thermal expansion coefficient between coating/substrate interface resulted in the poor adhesion strength, low load-carrying ability, easily deformation and cracking of hard a-C:H coatings during the wear process $[5,6]$. 
More recently, an innovative design involving multilayer and/or duplex diffusion/coating treatment is to improve the adhesion strength and tribological behavior of aluminum alloys, which includes $\mathrm{Al}_{2} \mathrm{O}_{3}$ /DLC coating [7], $\mathrm{Si} / \mathrm{SiC} / \mathrm{DLC}$ gradient layer [8], $\mathrm{TiB}_{2} / \mathrm{DLC}$ multi-layers [9] and AlN/Ti/TiN/DLC coatings [10]. It should be noted that when compared with single DLC coatings, the adhesion strength and tribological performance could be improved in certain degree by the multi-layer or gradient design within DLC-based coatings. However, several disadvantages still existed including the high surface roughness, inadequate film thickness, and relatively higher wear rate for thus multi-layered coatings on aluminum alloys.

In this letter, the possibilities of improving the adhesion of DLC-based coatings on aluminum alloy by fabricating $\mathrm{Ti} / \mathrm{TiN} / \mathrm{Si} /(\mathrm{TiC} / \mathrm{a}-\mathrm{C}: \mathrm{H})$ multi-layered coatings using a combined arc ion plating and magnetron sputtering processes were examined. The microstructure, hardness, and tribological performance of DLC-based coatings under dry and oil-lubricated conditions were also comparatively investigated.

\section{Experimental}

Aluminum alloys discs in our experiments are polished mechanically and immersed ultrasonically in alcohol for about 15 min prior to deposition. Ti/TiN/Si/(TiC/a-C:H) multi-layered coatings were deposited on aluminum alloys using a combined arc ion plating and magnetron sputtering process in the same chamber. First, Ti and TiN graded layers are deposited in a multi-arc ion plating setup at a bias voltage of $250 \mathrm{~V}$, the duty factor of $80 \%$, the $\mathrm{N}_{2} / \mathrm{Ar}$ gas flux ratio of 2, and an arc current of $80 \mathrm{~A}$. Second, a magnetron sputtering system is used to deposit $\mathrm{Si} /(\mathrm{TiC} / \mathrm{a}-$ $\mathrm{C}: \mathrm{H})$ layers, in which Si layer is firstly deposited at a RF power of $400 \mathrm{~W}$, a bias voltage of $-300 \mathrm{~V}$, and the duty factor of $50 \%$, finally TiC/a-C:H is deposited at a bias voltage of $-1,000 \mathrm{~V}$, the duty factor of $20 \%$.

Raman spectra are acquired to investigate the structure of the TiC/a-C:H coatings. The combined layer is also investigated by using a PHILIPS X'Pert Pro diffractometer with a $\mathrm{Cu}$ Ka radiation source. The hydrogen bonding of the top TiC/a-C:H layer was also studied using a Bruker IFS66V Fourier transformation infrared spectrometer (FTIR). FTIR spectra indicated that top top TiC/a-C:H layer was hydrogenated amorphous carbon coatings $(\mathrm{a}-\mathrm{C}: \mathrm{H})$. The phases in the multi-layered coatings were determined by means of X-ray diffraction (XRD) techniques. The microstructure of top $\mathrm{TiC} / \mathrm{a}-\mathrm{C}: \mathrm{H}$ layer is observed using a JEOL 3010 TEM. Surface morphology and cross-sectional structure of the as-deposited coatings were analyzed by JSM-6701F cold field Scanning electron

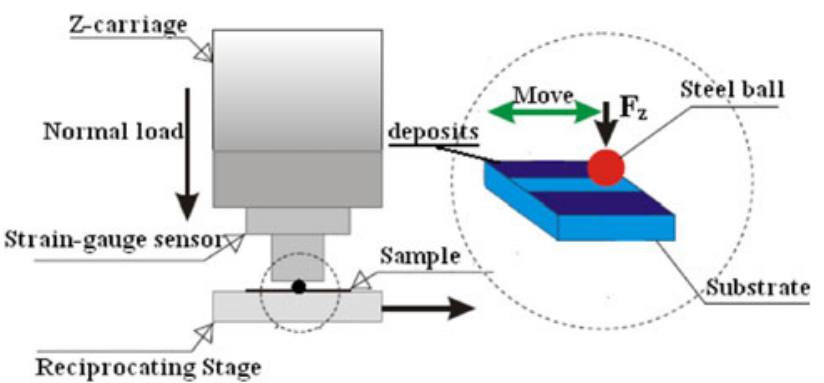

Fig. 1 Schematic diagram of the wear test for the coatings

microscope. The nanohardness of the coatings is determined by 600 Nano-indentation testers using a MTS threesided pyramidal diamond indenter.

The friction and wear behavior was tested on a reciprocating ball-on-disc tribo-meter at room temperature with a relative humidity of $30-35 \%$ under dry sliding condition and under oil-lubricated conditions. The lubrication oil used in this study was CF-4 diesel oil, which is commercially available from Great Wall Lubricant Corporation of China. Figure 1 is a schematic illustration of the wear test performed on the coatings; two-axis force sensors of electrical and mechanical design (strain-gauge type) for real friction coefficient measurement can measure simultaneously and independently a horizontal friction force and a vertical normal load. An AISI-52100 stainless steel ball (diameter $3 \mathrm{~mm}$ ) was used as the friction counter body. All tests were performed under a constant normal load of $5 \mathrm{~N}$ and a frequency of $5 \mathrm{~Hz}$ and a duration time of $2 \mathrm{~h}$. The friction coefficient and sliding time were recorded automatically and precisely during the test. Wear track morphology and profiles were analyzed by scanning electron microscopy (SEM) and a non-contact 3D surface profiler (model MicroMAXTM, made by ADE Phase Shift, Tucson, AZ, USA) after the wear test. The wear volume loss was determined from the wear track profiles. The wear rate of all the coatings was calculated using the equation: $K=V / S F$ where $V$ is the wear volume in $\mathrm{mm}^{3}, S$ is the total sliding distance in metres and $F$ is the normal load in newtons. The resulted wear rate of each sample was obtained by averaging three wear tests under the same wear conditions.

\section{Results and Discussion}

\subsection{Composition and Microstructure of the Multi-Layered Coatings}

The designed $\mathrm{Ti} / \mathrm{TiN} / \mathrm{Si} /(\mathrm{TiC} / \mathrm{a}-\mathrm{C}: \mathrm{H})$ multi-layered coatings on aluminum alloy were successfully deposited on aluminum alloys using a combined arc ion plating and 


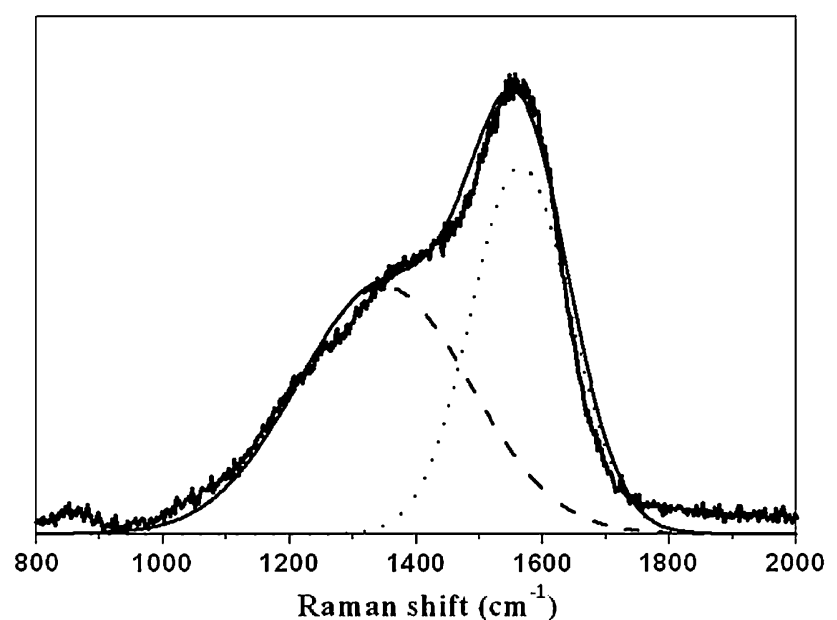

Fig. 2 Raman spectra of top TiC/a-C:H layer acquired between 800 and $2,000 \mathrm{~cm}^{-1}$

magnetron sputtering process in the same chamber in the present study. Figure 2 showed the Raman spectra of top TiC/a-C:H layer acquired between 800 and 2,000 $\mathrm{cm}^{-1}$, which can be deconvoluted into two sub-peaks: $G$ band (G means graphitic) around $1,565 \mathrm{~cm}^{-1}$ and $\mathrm{D}$ (D means disorder) band at approximately $1,348 \mathrm{~cm}^{-1}[7,8]$, which are typical characteristics of diamond-like carbon coatings. The top TiC/a-C:H composite layer is further investigated by high resolution TEM as shown in Fig. 3. HRTEM pictures clearly show that small crystalline grains in the range of 3-5 nm (black area distinguished by the lattice fringe contrast) were embedded in the amorphous (white area) matrix (Fig. 3a). Figure 3b clearly shows corresponding electron diffraction patterns of top Ti-DLC layer, diffraction rings from $\mathrm{TiC}$ (111) and (200) planes were close to each other and located near the transmission spot. The second brightest ring could be from the TiC (220) plane with the interplanar crystal spacing of $0.153 \mathrm{~nm}$. The outer diffraction rings originated from the $\mathrm{TiC}$ (311) and (222) planes. The further amplified image of lattice fringes (Fig. 3c) displayed some nanocrystalline $\mathrm{TiC}$ particles with the interplanar crystal spacing of $0.25 \mathrm{~nm}$, which is well in agreement with the typical TiC (111) crystal plane. High resolution TEM presented in Fig. 3 clearly reveals that the nanocrystalline $\mathrm{TiC}$ particles are homogeneously embedded in the a-C:H matrix and the doping of $\mathrm{Ti}$ in amorphous carbon matrix greatly promote the formation of an amorphous/crystalline nanocomposite micro-structure (namely, the formation of TiC/a-C:H top layer). Based on the literature, this amorphous/crystalline nanocomposite structure in $\mathrm{TiC} / \mathrm{a}-\mathrm{C}: \mathrm{H}$ top layer may be favorable to the high performance of mechanical properties owing to the following concepts [11, 12]: (i) combine $\mathrm{TiC}$ nano-crystalline and amorphous carbon matrix to achieve high hardness with good toughness; (ii) maintain $\mathrm{TiC}$ nanocrystalline size at several nm level to restrict crack and create a large volume of grain boundaries.

The multi-layered structure in $\mathrm{Ti} / \mathrm{TiN} / \mathrm{Si} /(\mathrm{TiC} / \mathrm{a}-\mathrm{C}: \mathrm{H})$ coatings was clearly confirmed in Fig. 4. EDS depth profiling (Fig. 4a) and the SEM micrographs of the fraction cross-sections (Fig. 4b) of coatings reflects very clearly the multilayer structure of the four layers (i.e., Ti, TiN, Si, and TiC/a-C:H). The whole thickness of multi-layered coatings on aluminum alloy substrates was approximately $4 \mu \mathrm{m}$.

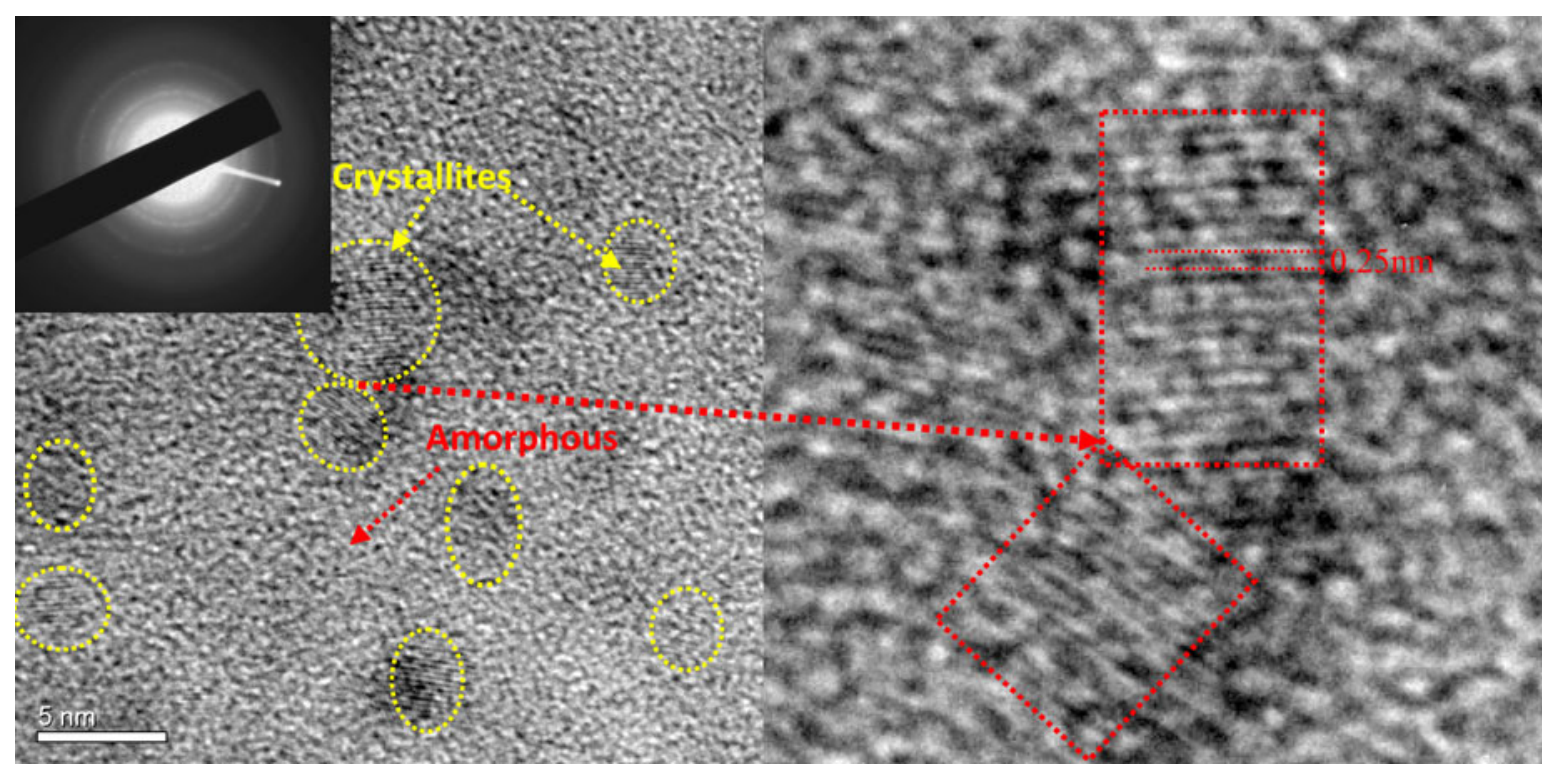

Fig. 3 HR-TEM micrographs of top TiC/a-C:H layer showing uniformly distributed and well separated TiC nanograins embedded in the amorphous carbon matrix 


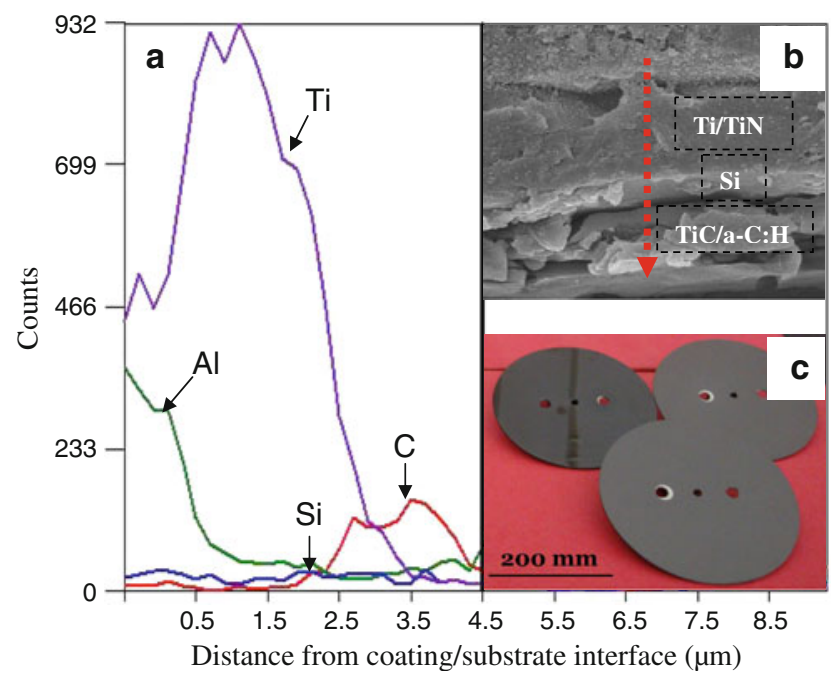

Fig. 4 a EDS depth profile of the Ti/TiN/Si/(TiC/a-C:H) coatings, b corresponding SEM micrographs of the fracture cross-sections; and c large-sized aluminum alloy samples coated by DLC-based multilayer with smooth surface and excellent adhesion with substrate

The profile indicates a Ti bonding layer of $\sim 200 \mathrm{~nm}$ thick, a TiN supporting layer of $\sim 2,300 \mathrm{~nm}$ thick, an interface $\mathrm{Si}$ layer between the TiN and top DLC layer of less than $150 \mathrm{~nm}$, and finally the top TiC/a-C:H layer of $\sim 1,500 \mathrm{~nm}$. The photo-micrographs also demonstrate that the supporting Ti/TiN/Si multi-layers are very dense, providing the top TiC/a-C:H layer with excellent load support.

\subsection{Gradient Distribution in Hardness of Multi-Layered Coatings}

The nano-hardness of the corresponding multi-layered coating varied with the thickness is showed in Fig. 5. The

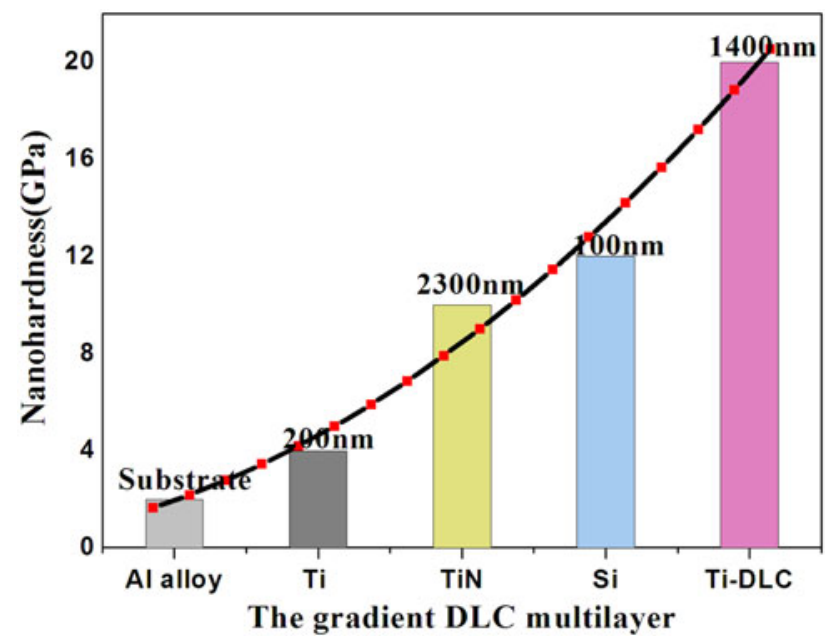

Fig. 5 Gradient distribution of nano-hardness in the cross-section of the as-deposited $\mathrm{Ti} / \mathrm{TiN} / \mathrm{Si} /(\mathrm{TiC} / \mathrm{a}-\mathrm{C}: \mathrm{H})$ multi-layered coatings on aluminum alloy substrates nano-hardness of aluminum alloy substrate is around $2 \mathrm{GPa}$. The Ti bonding layer with a thickness of $\sim 100 \mathrm{~nm}$ is about $4 \mathrm{GPa}$, a supporting TiN layer is approximately $10 \mathrm{GPa}$. In addition, the formation of $\mathrm{TiSi}_{x}$ compound can better modify the adhesion between amorphous silicon and TiN or Ti layer [13], consequently an interface Si layer with a hardness of $12 \mathrm{GPa}$ is thus fabricated. Finally, top TiC/a-C:H layer exhibited an highest hardness of approximately $20 \mathrm{GPa}$. As a result, such better hardness gradient in coatings effectively avoids the bigger hardness transition from $\mathrm{Al}$ substrate (very soft) to the upper DLC layer (very hard) and thus relieves the stress during the deposition process. This gradient design in hardness also greatly strengthens the adhesion strength between aluminum alloy and DLC nanocomposite coatings and improves the load carrying capacity.

The adhesion of the multi-layered Ti/TiN/Si/(TiC/a$\mathrm{C}: \mathrm{H})$ coatings on the aluminum alloy substrates was studied using a commercial scratch testing system equipped with an acoustic emission signal detecting system. The critical load, i.e., the normal load at the coating failure as detected using an acoustic emission detector, was accepted as a quantitative measure to evaluate the adhesion strength. The critical load was further verified by observing the corresponding SEM micrograph of a scratch pattern and the critical load of multi-layered coatings on Al alloys substrates are higher than $20 \mathrm{~N}$, which indicated the strong adhesion of coatings on $\mathrm{Al}$ alloys. In addition, the thermal shock tests of coatings were performed using the water quench tests, the specimens were heated to $200^{\circ} \mathrm{C}$ for $20 \mathrm{~min}$ in a furnace and then quenched into a container of water with a temperature of $20^{\circ} \mathrm{C}$ for $2 \mathrm{~min}$ before returning to the furnace. This procedure is repeated until the presence of macroscopical cracks or chipping failure of coating. Via thermal shock tests, characteristic of the interfacial bonding strength of multi-layered DLC-based coatings on aluminum alloy substrates is strongly influenced by the presence of residual thermal stresses, which is caused by the differential thermal contraction during sudden temperature change. Results show that after 30 thermal cycles the DLC-based multi-layered coatings on $\mathrm{Al}$ alloy exhibited no delamination or peeling from Al substrates. The higher thermal resistance of multi-layered DLC coatings indicated that the multi-layered design in composition and hardness can relax thermal stresses and resist the formation and propagation of cracks, therefore interfacial bonding strength between soft $\mathrm{Al}$ substrate and hard DLCbased coating can be improved significantly.

\subsection{Excellent Tribological Performance Under Dry and Oil-Lubricated Conditions}

The tribological behavior of $\mathrm{Ti} / \mathrm{TiN} / \mathrm{Si} /(\mathrm{TiC} / \mathrm{a}-\mathrm{C}: \mathrm{H})$ coating, single TiC/a-C:H(DLC) layer and aluminum alloy in 

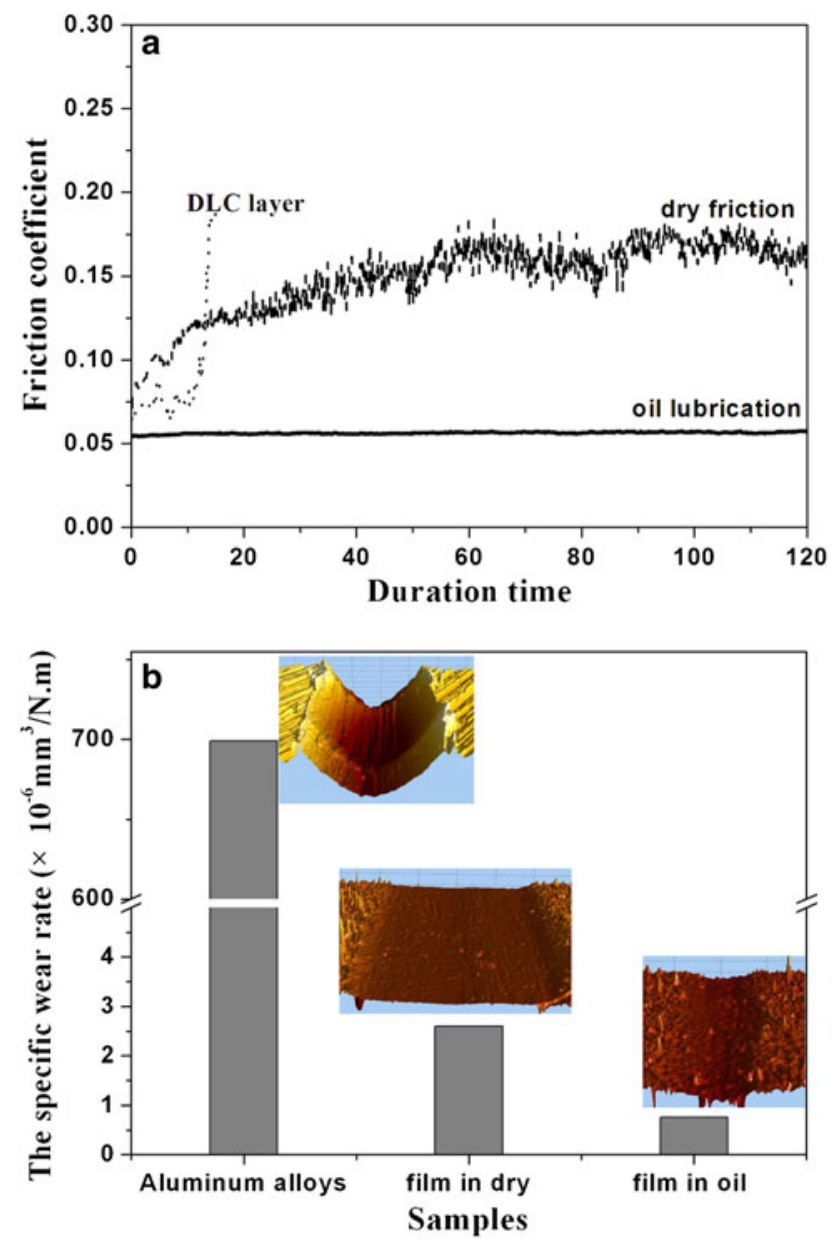

Fig. 6 The friction coefficient of Ti/TiN/Si/(TiC/a-C:H) multi-layered coatings versus the duration time in dry and oil-lubricated conditions (a); the specific wear rate of the Ti/TiN/Si/(TiC/a-C:H) multi-layered coatings in dry and oil-lubricated conditions (b), inset pictures are wear track profiles analyzed by non-contact 3D surface profiler after the wear test

dry and oil-lubricated conditions were comparatively investigated as shown in Fig. 6a. Under dry friction condition, aluminum alloys exhibit a very high friction coefficient of 0.38 , while the multi-layered coatings show the lower friction coefficient of 0.16 . However, the friction failure of single DLC layer occurs in a very short duration. Under the oil-lubricated conditions, multi-layered coatings exhibit a very low and stable friction coefficient of approximately 0.05 . Furthermore, the specific wear rate is shown in Fig. 6b. When compared with aluminum alloy, the wear rate of the multi-layered coatings was more than two orders of magnitude lower in dry wear condition and three orders of magnitude lower in oil-lubricated condition. Figure 7 shows the morphology of the wear tracks of aluminum alloy substrate (a), Ti/TiN/Si/(TiC/a-C:H) multilayered coatings in dry sliding conditions (b) and in oil lubrication conditions (c). The wear track (Fig. 7a) shows
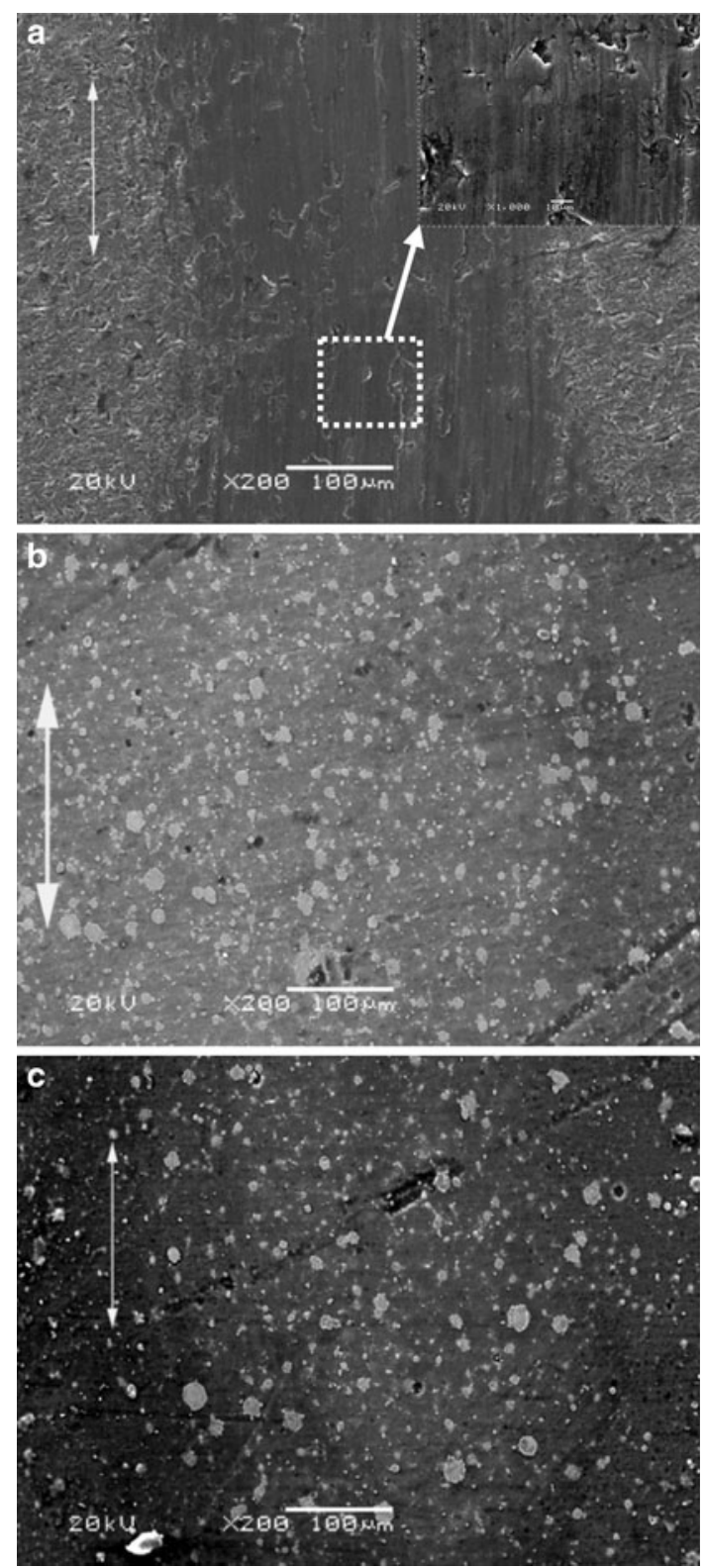

Fig. 7 Morphology of the wear tracks of aluminum alloy substrate (a); Ti/TiN/Si/(TiC/a-C:H) multi-layered coatings in dry sliding conditions (b) and in oil lubrication conditions (c)

the larger extent of adhesion wear and severe deformation in the sliding direction under the combined stresses of compression and shear, which results in larger wear rate of aluminum alloy. The morphology of the worn surface of multi-layered coatings under dry sliding condition is similar to that of multi-layered coatings tested at oil-lubricated condition. The worn surface of multi-layered coatings revealed slight wear and rather smooth surface with smaller damaged regions, only some small grooves and few dimples are noted on the worn surface (Fig. 7b, c).

For the wear failure of aluminum alloys, adhesion wear becomes critical and predominant [14]. The interesting 
results obtained in this article provide important design principles for the fabrication of self-lubricating, corrosion and wear resistant coatings as protective barrier for aluminum alloy parts. First, control of the structure and composition of the coatings at the micro/nano-scale is an exciting scientific subject combined with an industrial challenge. For tribological coatings, low internal stress and strong adhesion between "hard" coatings and "soft" aluminum substrates is critically important for a long service life [15]. In the present article, the thick supporting layers with high strength achieved by the micro-control of composition and microstructure on each sublayer effectively reduce the internal stress to a minimum [16]. Second, the assembly of a self-lubricating DLC top layer with excellent anti-adhesion wear properties is vital to the fabrication of such kinds of high-performance coatings on aluminum alloys. Finally, this illustrates that tribological performance of combined coatings can be further improved by optimizing the microstructure and composition without loss of strength or their nanostructural nature.

\section{Conclusions}

Gradient Ti/TiN/Si/(TiC/a-C:H) multi-layer on aluminum alloy was successfully fabricated on aluminum alloys by a combined arc ion plating and magnetron sputtering process. Multi-layered structure within DLC-based coatings has shown to significantly improve the load-bearing capacity, anti-wear, and self-lubricating ability of $\mathrm{Al}$ alloys. The significant improvement in the hardness and tribological performance of multi-layered coatings can be attributed to the multi-layered microstructure, gradient hardness distribution within coatings, and the solid lubrication effect of the top DLC layer. Such high-performance nanocomposite coatings on aluminum alloys with superior self-lubricating performance and higher wear resistance will be the "ideal" advanced protective coatings for soft aluminum alloys in a wide range of engineering applications.

Acknowledgments The authors are grateful to the National Natural Science Foundation of China (Grant No. 50772115 \& 50905178) and the 863 program of Chinese Ministry of Science and Technology (No. 2009AA03Z105) for financial support.

\section{References}

Miller, W.S., Zhuang, L., Bottema, J., Wittebrood, A.J., De Smet, P., Haszler, A., Vieregge, A.: Recent development in aluminium alloys for the automotive industry. Mater. Sci. Eng. A 280(1), 37-49 (2000)

Kim, S.K., Kim, T.H., Rie, K.-T.: TiCN Coatings on aluminum alloy formed by MO-PACVD. Surf. Coat. Technol. 131, 121-126 (2000)

Kano, M.: Super low friction of DLC applied to engine cam follower lubricated with ester-containing oil. Tribol. Int. 39, 1682-1685 (2006)

Pei, Y.T., Galvan, D., Strondl, C.: Advanced TiC/a-C nanocomposite coatings deposited by magnetron sputtering. J. Eur. Ceram. Soc. 26, 565-570 (2006)

Ouyang, J.H., Sasaki, S., Murakami, T.: Properties of titaniumcontaining diamond like carbon coatings. Wear 266(1-2), 96-102 (2009)

Sánchez-López, J.C., Martínez-Martínez, D., Fernández, A.: Tribological behaviour of titanium carbide/amorphous carbon nanocomposite coatings: from macro to the micro-scale. Surf. Coat. Technol. 202, 4011-4018 (2008)

Nie, X., Wilson, A., Leyland, A., Matthews, A.: Deposition of duplex $\mathrm{Al}_{2} \mathrm{O}_{3} / \mathrm{DLC}$ coatings on $\mathrm{Al}$ alloys for tribological applications using a combined micro-arc oxidation and plasma-immersion ion implantation technique. Surf. Coat. Technol. 121, 506-513 (2000)

Schwarz, Ch., Heeg, J., Rosenberg, M.: Investigation on wear and adhesion of graded $\mathrm{Si} / \mathrm{SiC} / \mathrm{DLC}$ coatings deposited by plasmaenhanced-CVD. Diam. Relat. Mater. 17, 1685-1688 (2008)

Rao, J., Cruz, R., Lawson, K.J.: Sputtered DLC-TiB 2 multilayer films for tribological applications. Diam. Relat. Mater. 14, 1805-1809 (2007)

Liao, J.X., Xia, L.F., Sun, M.R., Liu, W.M., Xue, Q.J.: The tribological properties of a gradient layer prepared by plasmabased ion implantation on 2024 aluminum alloy. Surf. Coat. Technol. 183, 157-164 (2004)

Voevdin, A.A., Zabinski, J.S.: Supertough wear-resistant coatings with 'chameleon' surface adaptation. Thin Solid Films 370, 223 231 (2000)

Voevdin, A.A., Zabinski, J.S.: Nanocomposite and nanostructured tribological materials for space applications. Compos. Sci. Technol. 65, 741-748 (2005)

Ezoe, K., Yamamoto, T., Ishii, K., Matsumoto, S.: The effect of elevated silicon substrate temperature on $\mathrm{TiSi}_{2}$ formation from a Ti film. Thin Solid Films 369, 244-247 (2000)

Torabian, H., Pathak, J.P., Tiwari, S.N.: Wear characteristics of Al-Si alloys. Wear 172, 49-58 (1994)

Xia, L.F., Yan, Z.H., Liao, J.X.: Effects of intermediate layers on the tribological behavior of DLC coated 2024 aluminum alloy. Wear 257, 599-605 (2004)

Wang, L.P., Zhang, J.Y., Hu, L.T., Xue, Q.J.: Fabrication of a nanocrystalline $\mathrm{Ni}-\mathrm{Co} / \mathrm{CoO}$ functionally graded layer with excellent electrochemical corrosion and tribological performance. Nanotechnology 17, 4614-4623 (2006) 